\title{
Clinical utility of transthoracic echocardiography for screening abdominal aortic aneurysm: a prospective study in a Japanese population
}

Yoshihisa Matsumura ${ }^{1 *}$, Michiko Wada², Daigo Hirakawa², Yuka Yasuoka², Norihito Morimoto², Hiroaki Takeuchi', Hiroaki Kitaoka ${ }^{3}$, Kazumasa Orihashi ${ }^{4}$ and Tetsuro Sugiura ${ }^{1}$

\begin{abstract}
Background: The aim of the present study was to evaluate the clinical utility of transthoracic echocardiography (TTE) for screening abdominal aortic aneurysm (AAA) and to identify important TTE indices associated with AAA in a Japanese population.

Methods: We prospectively studied 1912 patients who were referred for TTE. AAA was defined as $\geq 30 \mathrm{~mm}$ in size.

Results: The abdominal aorta was visualized in $95.1 \%$ (1818/1912) by TTE. AAA was identified in $2.6 \%$ (47/1818). The aortic root size was significantly larger in patients with AAA than those without ( $36.0 \pm 4.1 \mathrm{vs} .31 .7 \pm 4.2 \mathrm{~mm}$, $p<0.001)$. The aortic root size had a fair correlation with abdominal aortic size $(r=0.31, p<0.001)$. The aortic root size of $\geq 34 \mathrm{~mm}$ was predictive of AAA by receiver operating characteristic curve analysis (area under the curve $=0.78$, $p<0.001$ ). Multiple logistic regression analysis revealed that aortic root size (Hazard ratio 1.23, $p<0.001$ ) and age (Hazard ratio 1.05, $p=0.013$ ) were the independent predictors of AAA.
\end{abstract}

Conclusions: The feasibility of the abdominal aortic visualization during TTE was excellent. The aortic root size measured by TTE was the independent predictor of AAA. Screening for AAA during TTE appeared to be useful especially in the older patients with a large ( $\geq 34 \mathrm{~mm}$ ) aortic root.

Keywords: Abdominal aortic aneurysm, Aortic root, Echocardiography, Screening

\section{Background}

Abdominal aortic aneurysm (AAA), an abnormal focal dilation of the abdominal aorta, is a common and potentially life-threatening condition [1]. Only a half of patient with ruptured AAA can reach the hospital alive with an additional high operative mortality of $49 \%$ [2]. In asymptomatic patients with AAA, elective repair of AAA is the most effective management to prevent the rupture of AAA with a low procedure mortality $[3,4]$. Thus, early identification and elective repair of AAA is clinically important. Most of the patients with rupture have an undiscovered AAA [5], because AAA is mostly asymptomatic and occult

\footnotetext{
* Correspondence: matsumur@kochi-u.ac.jp

'Department of Laboratory Medicine, Kochi Medical School, Kochi University,

Oko-cho, Nankoku-shi, Kochi 783-8505, Japan

Full list of author information is available at the end of the article
}

on physical examination. Abdominal ultrasound, a fast and safe screening method to detect AAA with high sensitivity and specificity, is recommended for screening the patients who are at high risk of AAA [6]. Although screening for AAA during transthoracic echocardiography (TTE) has been reported to be clinically useful in Western populations [7-16], little is known about the important TTE indices associated with the presence of AAA [12, 14, 16]. Accordingly, the aim of this study was to evaluate the clinical utility of TTE for screening AAA and to identify important TTE indices associated with AAA in a Japanese population.

\section{Methods}

\section{Study population}

We prospectively examined 1912 consecutive patients who were referred for routine TTE from June 2013 to May 2014 
at Kochi Medical School Hospital. Clinical data were obtained by chart reviews. The study was approved by the Ethics Committee on Human Research of the Kochi Medical School and all the patients gave written informed consent before the study. Patients with prior AAA repair or aortic dissection were excluded from the study.

\section{Echocardiography}

Echocardiographic evaluation of the aorta was performed by 3 registered sonographers (M.W., D.H., and Y.Y.) in our echocardiographic laboratory. Routine transthoracic 2-dimensional, M-mode, and Doppler echocardiography were performed as recommended by the American Society of Echocardiography [17]. The aortic root size was measured at the level of the sinus of Valsalva from the parasternal long-axis view at the onset of the QRS complex. We used 4 echocardiographic equipments as follows: 1) Vivid7 (General Electric, Horten, Norway) with a $3 \mathrm{~S}$ transducer (1.5 to $3.6 \mathrm{MHz}$ variable-frequency), 2) iE33 (Philips, Andover, MA, USA) with an S5-1 transducer (1 to $5 \mathrm{MHz}$ variable-frequency), 3) Vivid Q(General Electric, Horten, Norway) with a M4S transducer (1.5 to $3.6 \mathrm{MHz}$ variable-frequency), 4) Prosound $\alpha 7$ (Hitachi-Aloka Medical, Tokyo, Japan) with a UST-52105 transducer (3.5 to 5.0 $\mathrm{MHz}$ variable-frequency transducer).

In succession to routine TTE, the abdominal aorta was visualized in the supine position using the same cardiac transducer within a short period of time. First, longitudinal image of the abdominal aorta was visualized. Secondly, transverse image of the abdominal aorta was visualized. The abdominal aorta was scanned from the subcostal position and then traced distally as far as possible. Size of the abdominal aorta was measured using still-frame images and 'on-line' video calipers in diastole at the onset of the QRS complex at the longitudinal and transverse images. The maximal size of the abdominal aorta $\geq 30 \mathrm{~mm}$ in either anteroposterior or lateral size was defined as AAA. Clinical information was collected using the TTE requisition slip and the electrical recording system. In randomly selected 15 patients, we measured the additional examination time for screening AAA.

\section{Statistical analysis}

Categorical variables were presented as total number and $\%$ of patients, and continuous variables were presented as means \pm standard deviation. Clinical and TTE indices between the 2 groups were compared with chisquare test for categorical variables and Wilcoxon ranksum test for continuous variables. Correlation between the aortic root and the abdominal aorta sizes was evaluated using linear regression analysis. Receiver operating characteristic curve analysis was used to determine the discriminating cutoff value for predicting AAA. Multiple logistic regression analysis was used to determine statistically significant variables associated with AAA. A $p$ value $<0.05$ was considered statistically significant. Data were statistically analyzed using the JMP version 11.0 software (SAS Institute Inc., Cary, NC, USA).

\section{Results}

Feasibility of AAA screening during TTE

Among 1912 patients, the abdominal aorta was visualized in $95.1 \%(1818 / 1912)$ of the patients. The additional examination time for abdominal screening was less than a minute; the average time for abdominal aorta screening was $31.4 \pm 12.3$ (ranged from 13.0 to 53.0 ) seconds in randomly selected 15 patients. TTE was performed with Vivid7 in $36 \%$, with iE33 in $34 \%$, with Vivid Q in $17 \%$, and with Prosound $\alpha 7$ in $13 \%$ of the patients.

\section{Patient characteristics}

We analyzed 1818 patients in whom adequate visualization of the abdominal aorta were obtained. Forty-one percent (746/1818) were inpatients and $49 \%$ (897/1818) were men with a mean age of $67.4 \pm 15.8$ years. The clinical and echocardiographic diagnosis of the study patients were: ischemic heart disease (24\%), valvular disease (23\%), myocardial disease (22\%), arrhythmia (7\%), congenital heart disease (3\%), ventricular hypertrophy (3\%), pulmonary hypertension (2\%), cardiac mass (1\%), normal echocardiogram (12\%) and others (3\%). The mean size of the abdominal aorta was $17.2 \pm 5.5 \mathrm{~mm}$.

\section{Prevalence of AAA}

AAA was identified in $2.6 \%$ (47/1818). The prevalence of AAA was $3.9 \%(35 / 897)$ in men and $1.3 \%(12 / 921)$ in women $(p<0.001)$. The mean size of AAA was $43.6 \pm 10.7$ (30.0 to 90.0$) \mathrm{mm}$, with 34 patients (72.3\%) having an aortic diameter $\geq 40 \mathrm{~mm}$. Of the 47 patients with AAA, $29.7 \%(14 / 47)$ underwent surgical repair or endovascular aortic stent graft insertion during 12 months following the TTE. AAA was previously known in 30 patients and unknown in 17 patients. Thirty-four of the 47 patients with AAA (72 \%) had a prior or current history of smoking, 33 (70 \%) had hypertension, and 26 (55 \%) had ischemic heart disease.

\section{Clinical and TTE indices associated with the presence of AAA}

Clinical and TTE indices in patients with and without AAA are shown in Table 1 . The patients with AAA were significantly older than those without (77 \pm 9 vs. $67 \pm$ 16 years, $p<0.001)$. AAA was not found before the age of 54 years. AAA was significantly more frequent in male patients than female patients. The prevalence of AAA in male patients aged $\geq 55$ years was $4.6 \%$ (35/765). 
Table 1 Comparison of clinical and echocardiographic indices

\begin{tabular}{|c|c|c|c|}
\hline \multirow[t]{2}{*}{ Variables } & \multirow{2}{*}{$\begin{array}{l}\text { AAA } \\
(+)\end{array}$} & \multirow{2}{*}{$\begin{array}{l}\text { AAA } \\
(-)\end{array}$} & \multirow[t]{2}{*}{$p$ value } \\
\hline & & & \\
\hline Age (years) & $77 \pm 9$ & $67 \pm 16$ & $<0.001$ \\
\hline Men, n (\%) & $35(75 \%)$ & $862(49 \%)$ & 0.001 \\
\hline Aortic root (mm) & $36.0 \pm 4.1$ & $31.7 \pm 4.2$ & $<0.001$ \\
\hline Left atrium (mm) & $37.3 \pm 6.9$ & $38.1 \pm 7.7$ & 0.664 \\
\hline $\begin{array}{l}\text { Interventricular septal thickness } \\
(\mathrm{mm})\end{array}$ & $9.7 \pm 1.4$ & $9.6 \pm 2.0$ & 0.323 \\
\hline LV posterior wall thickness (mm) & $9.7 \pm 1.1$ & $9.3 \pm 1.5$ & 0.018 \\
\hline LV end-diastolic dimension (mm) & $47.8 \pm 4.3$ & $46.2 \pm 6.1$ & 0.010 \\
\hline LV end-systolic dimension (mm) & $31.0 \pm 5.5$ & $28.8 \pm 7.0$ & 0.001 \\
\hline LV fractional shortening (\%) & $34.9 \pm 7.8$ & $37.8 \pm 8.5$ & 0.001 \\
\hline LV mass (g) & $\begin{array}{l}168.1 \pm \\
41.2\end{array}$ & $\begin{array}{l}156.0 \pm \\
51.9\end{array}$ & 0.016 \\
\hline $\mathrm{E}(\mathrm{cm} / \mathrm{sec})$ & $59.6 \pm 18.1$ & $70.6 \pm 23.8$ & 0.001 \\
\hline $\mathrm{A}(\mathrm{cm} / \mathrm{sec})$ & $85.3 \pm 25.2$ & $79.6 \pm 24.6$ & 0.192 \\
\hline$E / A$ & $0.75 \pm 0.37$ & $0.93 \pm 0.47$ & 0.001 \\
\hline E deceleration time (msec) & $\begin{array}{l}247.1 \pm \\
61.5\end{array}$ & $\begin{array}{l}232.8 \pm \\
65.8\end{array}$ & 0.109 \\
\hline $\mathrm{E}^{\prime}(\mathrm{cm} / \mathrm{sec})$ & $5.3 \pm 1.8$ & $6.6 \pm 2.5$ & 0.001 \\
\hline $\mathrm{A}^{\prime}(\mathrm{cm} / \mathrm{sec})$ & $9.5 \pm 2.3$ & $9.3 \pm 2.3$ & 0.960 \\
\hline $\mathrm{S}^{\prime}(\mathrm{cm} / \mathrm{sec})$ & $6.4 \pm 1.8$ & $7.0 \pm 1.9$ & 0.022 \\
\hline$E / E^{\prime}$ & $12.2 \pm 5.9$ & $11.8 \pm 5.6$ & 0.568 \\
\hline
\end{tabular}

Data are presented as mean $\pm S D$ or $n(\%)$. $L V$, left ventricular. E, Early diastolic LV inflow velocity; A, Late diastolic LV inflow velocity; $E^{\prime}$, early diastolic septal mitral annular velocity; $A^{\prime}$, late diastolic septal mitral annular velocity; $S^{\prime}$, systolic septal mitral annular velocity; $T \mathrm{TE}=$ Transthoracic echocardiography; $\mathrm{AAA}=$ abdominal aortic aneurysm

There were significant differences in the aortic root size, left ventricular (LV) posterior wall thickness, LV end-diastolic dimension, LV end-systolic dimension, LV fractional shortening, LV mass, early diastolic LV inflow velocity, early diastolic LV inflow velocity/ late diastolic LV inflow velocity, early diastolic septal mitral annular velocity, and systolic septal mitral annular velocity between patients with and without AAA.

The aortic root size measured by TTE was significantly larger in patients with AAA than those without $(36.0 \pm 4.1$ vs. $31.7 \pm 4.2 \mathrm{~mm}, p<0.001$ ) (Fig. 1). All patients with AAA had aortic root size of $\geq 28 \mathrm{~mm}$. The aortic root size correlated significantly with the abdominal aortic size $(\mathrm{r}=0.31$, $p<0.001$ ) (Fig. 2). The aortic root size of $\geq 34 \mathrm{~mm}$ was predictive of AAA by receiver operating characteristic curve analysis (area under the curve $=0.78$, sensitivity: $70 \%$, specificity: $70 \%, p<0.001)$. Multiple logistic regression analysis using 12 variables revealed that aortic root size (Hazard ratio 1.23, $p<0.001$ ) and age (Hazard ratio $1.05, p=0.013)$ were the independent predictors of AAA (Table 2).

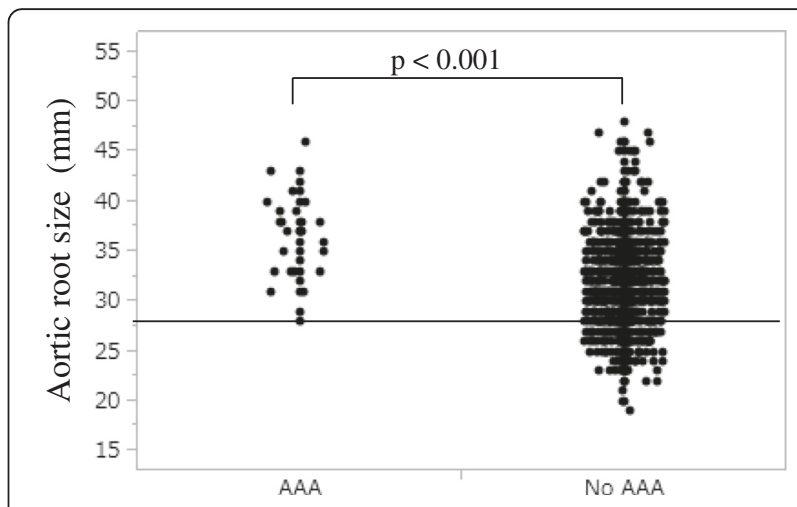

Fig. 1 The aortic root size in patients with and without AAA. The aortic root size was significantly larger in patients with AAA than those without ( $36.0 \pm 4.1$ vs. $31.7 \pm 4.2 \mathrm{~mm}, p<0.001)$. All patients with AAA had the aortic root size of $\geq 28 \mathrm{~mm}$. AAA = abdominal aortic aneurysm

\section{Discussion}

The present study had 3 major findings. First, the feasibility of the abdominal aortic visualization during TTE was excellent (95.1\%). Second, the prevalence of AAA during TTE was $2.6 \%$. Third, the aortic root size measured by TTE was the independent predictor of AAA.

Reynolds $\mathrm{T}$ et al. firstly reported in 1990 that evaluation of the abdominal aorta should be carried out during a routine TTE examination [18]. Afterwards, other authors have reported usefulness of TTE for screening AAA [7-16], because of excellent feasibility and relatively high prevalence of AAA.

The success rate of abdominal aortic imaging during TTE has been reported to range from 79 to $96 \%$ with an additional time range from 0.5 to $8 \mathrm{~min}$ for examination [7-16]. In the present study, we used the same cardiac transducer, so that no additional equipment was required.

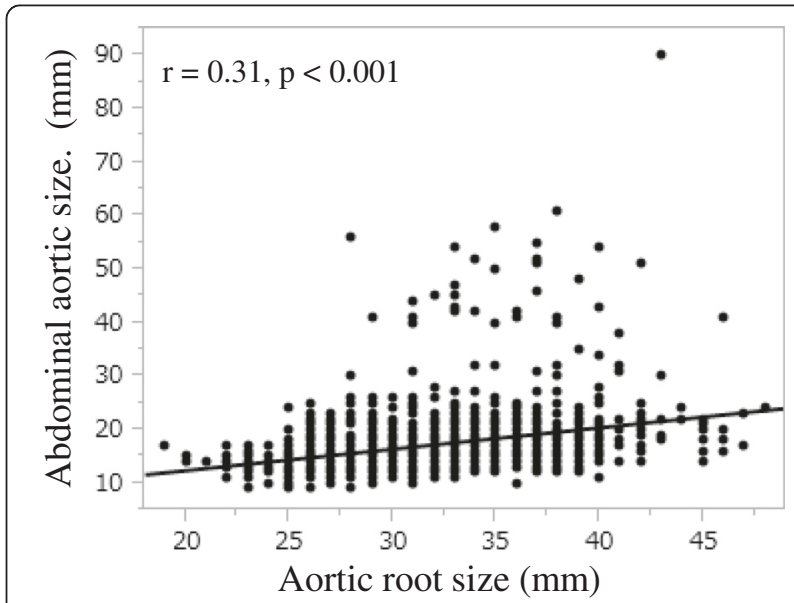

Fig. 2 Correlation between the aortic root and the abdominal aorta sizes. The aortic root size correlated significantly with the abdominal aortic size $(r=0.31, p<0.001)$ 
Table 2 Multiple logistic regression analysis for predicting AAA

\begin{tabular}{lccl}
\hline Variables & Hazard ratio & $95 \% \mathrm{Cl}$ & $p$ value \\
\hline Age (years) & 1.05 & $1.01-1.09$ & 0.013 \\
Men, $\mathrm{n}(\%)$ & 1.27 & $0.57-2.90$ & 0.562 \\
Aortic root (mm) & 1.23 & $1.13-1.33$ & $<0.001$ \\
LV posterior wall thickness (mm) & 1.55 & $0.93-2.67$ & 0.10 \\
LV end-diastolic dimension (mm) & 1.23 & $0.98-1.53$ & 0.067 \\
LV end-systolic dimension (mm) & 0.90 & $0.75-1.14$ & 0.352 \\
LV fractional shortening (\%) & 0.94 & $0.86-1.06$ & 0.242 \\
LV mass (g) & 0.98 & $0.95-0.99$ & 0.054 \\
E (cm/sec) & 1.00 & $0.97-1.02$ & 0.741 \\
E/A & 0.68 & $0.17-1.70$ & 0.489 \\
$E^{\prime}(\mathrm{cm} / \mathrm{sec})$ & 0.92 & $0.69-1.18$ & 0.558 \\
$\mathrm{~S}^{\prime}(\mathrm{cm} / \mathrm{sec})$ & 0.86 & $0.66-1.10$ & 0.235 \\
\hline
\end{tabular}

Data are presented as mean \pm SD or $n(\%)$. LV, left ventricular. E, Early diastolic LV inflow velocity; A, Late diastolic LV inflow velocity; E', early diastolic septal mitral annular velocity; $A^{\prime}$, late diastolic septal mitral annular velocity; $S^{\prime}$, systolic septal mitral annular velocity; $\mathrm{AAA}=$ abdominal aortic aneurysm; $\mathrm{Cl}$, confidence interval

Moreover, an additional examination time for abdominal visualization was less than a minute in randomly selected 15 patients. These results suggest that screening of the abdominal aorta during TTE is feasible with minimal additional time and cost compared to separate abdominal ultrasound examination.

The prevalence of AAA during TTE has been reported to range from $2.2 \%$ to $6.5 \%$ in Western countries [7-16], whereas the prevalence of AAA using abdominal ultrasound ranged from $3.0 \%$ to $8.0 \%$ from population screening surveys in Western countries [19]. Therefore, previous studies have demonstrated that screening for AAA during TTE is clinically useful [7-16]. However, Seelig MH et al. demonstrated that TTE performed in a highly selected cardiac patient group in a tertiary referral center is not a useful tool for screening clinically unsuspected AAA [20], because the prevalence of AAA was low $(0.8 \%)$ and only $16 \%$ of the patients with AAA underwent surgical repair following TTE. In Korean population [21], detection rate of AAA was $0.5 \%$ during TTE indicating that the prevalence of AAA in Asia is lower than that in Western countries. Despite the low prevalence of AAA, a routine examination of the abdominal aorta during TTE appeared to be an effective preventive strategy for life-threatening but asymptomatic AAA, because $26 \%$ of the patients with AAA underwent surgical repair or endovascular aortic stent graft insertion following the TTE. In the present study, the prevalence of AAA during TTE was $2.6 \%$. Moreover, $30 \%$ of the patients of the present study with AAA underwent aortic repair following the TTE. These results suggest that screening for AAA during TTE also appeared to be clinically useful in a Japanese population.
Among the TTE indices associated with the presence of AAA, LV hypertrophy, LV dilatation, or low LV fractional shortening are likely relate to hypertension; $70 \%$ of the patients with AAA had hypertension. Although Bekkers SC et al. reported that patients with AAA had dilated ascending aorta [12], little is known about the clinical importance of the aortic root size in association with AAA [14, 22]. Recently, Aboyans et al. have reported that the ascending aorta is larger in patients with AAA than those without by univariate analysis [16], though it is unknown about the exact position of measurement of the ascending aorta. Agricola E et al. have also demonstrated a high prevalence of dilatation/aneurysm of the ascending aorta and the aortic arch in patients with AAA evaluated by TTE [23]. These studies suggest a significant correlation between dilatation of the ascending aorta and the arch and AAA. However, discriminating cutoff value of the ascending aortic size for predicting AAA was not determined. Multivariate analysis was also not used to determine the significance of the ascending aortic size in association with AAA. Thus, it still remains unknown whether the ascending aortic size is important TTE indices for screening AAA.

In contrast, we measured the aortic root size at the level of the sinus of Valsalva. The aortic root size of $\geq 34 \mathrm{~mm}$ was predictive of AAA by receiver operating characteristic curve analysis. The aortic root size was the independent TTE index associated with the presence of AAA. As the common risk factors for AAA and atherosclerosis may lead to the aortic root dilatation, considering the fact that aortic root size and age were independent predictors of AAA, our study indicate that screening for AAA during TTE can be useful especially in the older patients with a large $(\geq 34 \mathrm{~mm})$ aortic root size. Although screening for AAA during TTE has been reported to be useful [7-16], the screening limiting to the older patients with a large $(\geq 34 \mathrm{~mm})$ aortic root size can be clinically efficient.

The present study has several limitations. First, the incidence of AAA depends on patient selection. However, the prevalence of AAA of $2.6 \%$ in the present study was not significantly different of that reported in Western countries $(2.2 \%$ to $6.5 \%)$. Second, AAA was incidentally discovered before the present study at least in 18 patients $(60 \%)$ as the result of other abdominal imaging studies obtained to evaluate an unrelated condition such as spine magnetic resonance imaging, computed tomography, or abdominal ultrasound, though the reasons for diagnosis of AAA were not available in the other 12 patients. The increasing use of imaging modalities has revealed asymptomatic and previously undiagnosed AAA. Therefore, we did not exclude patients with previously known AAA. Third, the atherosclerotic risk factors in patients with AAA were only available concerning a prior or current history of smoking, hypertension, and ischemic heart disease in the 
present study. Moreover, the atherosclerotic risk factors in patients without AAA were not available. The lack of information on the prevalence of traditional risk factors for atherosclerosis in patients with and without AAA does not allow stratifying the patients more likely to have AAA, according to atherosclerotic risk profile. Fourth, early detection of small AAA during TTE could cause needless disease labeling and anxiety resulting in psychological harm. Further studies are required to verify the clinical usefulness, cost-effectiveness, and psychological harm of AAA screening during TTE in different healthcare settings.

\section{Conclusions}

Visualization of the abdominal aorta during TTE is feasible with little additional time and cost. The aortic root size was the important TTE index associated with the presence of AAA. Screening for AAA during TTE was especially useful in the older patients with a large $(\geq 34 \mathrm{~mm})$ aortic root size.

\section{Abbreviations}

AAA: Abdominal aortic aneurysm; TTE: Transthoracic echocardiography; LV: Left ventricular.

\section{Competing interests}

The authors declare that they have no competing interests.

\section{Authors' contributions}

YM was contributed to analysis and interpretation of data and designed the study and drafted the manuscript. HK, KO and TS were contributed to conception and design of the study and to acquisition of data and were involved in revising the manuscript. $\mathrm{MW}, \mathrm{DH}$, and $\mathrm{YY}$ were contributed to acquisition and interpretation of data. NM and HT were involved in drafting the manuscript and revising it. All authors read and approved the final manuscript.

\section{Author details}

'Department of Laboratory Medicine, Kochi Medical School, Kochi University, Oko-cho, Nankoku-shi, Kochi 783-8505, Japan. ${ }^{2}$ Clinical Laboratory, Kochi Medical School, Kochi University, Kochi, Japan. ${ }^{3}$ Department of Cardiology, Neurology, and Aging Science, Kochi Medical School, Kochi University, Kochi, Japan. ${ }^{4}$ Department of Cardiovascular Surgery, Kochi Medical School, Kochi University, Kochi, Japan.

Received: 25 November 2015 Accepted: 6 February 2016

Published online: 12 February 2016

\section{References}

1. Sakalihasan N, Limet R, Defawe OD. Abdominal aortic aneurysm. Lancet. 2005;365:1577-89.

2. Hoornweg LL, Storm-Versloot MN, Ubbink DT, Koelemay MJ, Legemate DA, Balm R. Meta analysis on mortality of ruptured abdominal aortic aneurysms. Eur J Vasc Endovasc Surg. 2008;35:558-70.

3. Brady AR, Fowkes FG, Greenhalgh RM, Powell JT, Ruckley CV, Thompson SG. Risk factors for postoperative death following elective surgical repair of abdominal aortic aneurysm: results from the UK Small Aneurysm Trial, on behalf of the UK Small Aneurysm Trial participants. Br I Surg. 2000;87:742-9.

4. Dillavou ED, Muluk SC, Makaroun MS. Improving aneurysm-related outcomes: nationwide benefits of endovascular repair. J Vasc Surg. 2006;43:446-51.

5. Gloviczki P, Pairolero PC, Mucha Jr P, Farnell MB, Hallett Jr JW, Ilstrup DM, Toomey BJ, Weaver AL, Bower TC, Bourchier RG, Cherry Jr KJ. Ruptured abdominal aortic aneurysms: repair should not be denied. J Vasc Surg. 1992; 15:851-7.

6. Rooke TW, Hirsch AT, Misra S, Sidawy AN, Beckman JA, Findeiss LK, Golzarian J, Gornik HL, Halperin JL, Jaff MR, Monet GL, Olin JW, Stanley JC,White CJ, White JV, Zierler R, Hirsch AT, Haskal ZJ, Hertzer NR, Bakal CW, Creager MA, Halperin JL, Hiratzka LF, Murphy WR, Olin JW, Puschett JB, Rosenfield KA,
Sacks D, Stanley JC, Taylor LM Jr, White CJ, White JV, White RA, Jacobs AK, Anderson JL, Albert N, Creager MA, Ettinger SM, Guyton RA, Halperin JL, Hochman JS, Kushner FG, Magnus OE, Stevenson W, Yancy CW. 2011 ACCF/ AHA Focused Update of the Guideline for the Management of patients with peripheral artery disease (Updating the 2005 Guideline): a report of the American College of Cardiology Foundation/American Heart Association Task Force on practice guidelines. Circulation. 2011;124:2020-45.

7. Eisenberg MJ, Geraci SJ, Schiller NB. Screening for abdominal aortic aneurysms during transthoracic echocardiography. Am Heart J. 1995;130:109-15.

8. Schwartz KV, Rashkow AM, Akella MS. Detection of abdominal aortic aneurysm during routine echocardiography. Echocardiography. 1996;13:71-4.

9. Spittell PC, Ehrsam JE, Anderson L, Seward JB. Screening for abdominal aortic aneurysm during transthoracic echocardiography in a hypertensive patient population. J Am Soc Echocardiogr. 1997;10:722-7.

10. Jaussi A, Fontana P, Mueller XM. Imaging of the abdominal aorta during examination of patients referred for transthoracic echocardiography. Schweiz Med Wochenschr. 1999;129:71-6.

11. Giaconi S, Lattanzi F, Orsini E, Prosperi R, Tartarini G. Feasibility and accuracy of a rapid evaluation of the abdominal aorta during routine transthoracic echocardiography. Ital Heart J. 2003;4:332-6.

12. Bekkers SC, Habets JH, Cheriex EC, Palmans A, Pinto Y, Hofstra L, Crijns HJ. Abdominal aortic aneurysm screening during transthoracic echocardiography in an unselected population. J Am Soc Echocardiogr. 2005;18:389-93.

13. Ruggiero M, Lenti ML, Cavallari D, Dicillo CP, Mascolo AR, Musci S, Tota F, Sabato G, Tortorella C, Damiani D, Colonna P, Franchini G. Screening for abdominal aortic aneurysm during transthoracic echocardiography. A prospective study in 1202 consecutive patients at high risk: incidence, correlation with risk factors, feasibility, diagnostic accuracy, and increase in echocardiography time. G Ital Cardiol. 2006;7:217-23.

14. Roshanali F, Mandegar MH, Yousefnia MA, Mohammadi A, Baharvand B. Abdominal aorta screening during transthoracic echocardiography. Echocardiography. 2007;24:685-8.

15. Gentille-Lorente DI, Salvadó-Usach T. Screening for abdominal aortic aneurysm by means of transthoracic echocardiography. Rev Esp Cardiol. 2011;64:395-400.

16. Aboyans V, Bataille V, Bliscaux P, Ederhy S, Filliol D, Honton B, Kurtz B, Messas E, Mohty D, Brochet E, Kownator S. Effectiveness of screening for abdominal aortic aneurysm during echocardiography. Am J Cardiol. 2014; 114:1100-4.

17. Lang RM, Bierig M, Devereux RB, Flachskampf FA, Foster E, Pellikka PA, Picard MH, Roman MJ, Seward J, Shanewise JS, Solomon SD, Spencer KT, Sutton MS, Stewart WJ. Recommendations for chamber quantification: a report from the American society of echocardiography's guidelines and standards committee and the chamber quantification writing group, developed in conjunction with the European association of echocardiography, a branch of the European society of cardiology. J Am Soc Echocardiogr. 2005:18:1440-63.

18. Reynolds T, Santos T, Weidemann J, Langenfeld K, Warner MG. The evaluation of the abdominal aorta: a "how-to" for cardiac sonographers. J Am Soc Echocardiogr. 1990;3:336-46.

19. Wilmink $A B$, Quick CR. Epidemiology and potential for prevention of abdominal aortic aneurysm. Br J Surg. 1998;85:155-62.

20. Seelig MH, Malouf YL, Klingler PJ, Oldenburg WA, Atkinson EJ. Clinical utility of routine screening for abdominal aortic aneurysm during echocardiography. Vasa. 2000;29:265-8.

21. Oh SH, Chang SA, Jang SY, Park SJ, Choi JO, Lee SC, Park SW, Oh JK, Kim DK Routine screening for abdominal aortic aneurysm during clinical transthoracic echocardiography in a Korean population. Echocardiography. 2010;27:1182-7.

22. Aboyans V, Kownator S, Lafitte M, Brochet E, Emmerich J, Tribouilloy C, Lafitte S, Ferrini M. Working Group for Vascular Diseases/Thrombosis, French Society of Cardiology; Council of Echocardiography, French Society of Cardiology. Screening abdominal aorta aneurysm during echocardiography: literature review and proposal for a French nationwide study. Arch Cardiovasc Dis. 2010;103:552-8.

23. Agricola E, Slavich M, Tufaro V, Fisicaro A, Oppizzi M, Melissano G, Bertoglio L, Marone E, Civilini E, Margonato A, Chiesa R. Prevalence of thoracic ascending aortic aneurysm in adult patients with known abdominal aortic aneurysm: an echocardiographic study. Int J Cardiol. 2013;168:3147-8. 